\title{
Influence of Cable Lengths on EMI Emissions of a DC/DC Converter
}

\author{
Baghdadi Benazza ${ }^{1,2 *}$, Abdelber Bendaoud ${ }^{2}$, Jean-Luc Schanen ${ }^{3}$ \\ ${ }^{1}$ Laboratory of Applications of Plasma, Electrostatics and Electromagnetic Compatibility (APELEC), Djillali Liabès \\ University of Sidi Bel-Abbès, Sidi Bel-Abbés 22000, Algeria \\ ${ }_{2}^{2}$ Electrical Engineering Department, University Center Belhadj Bouchaib of Ain Temouchent, Ain Temouchent 46000, Algeria \\ ${ }^{3}$ G2Elab, CNRS, G-INP (Inst. of Eng. Univ Grenoble Alps), University of Grenoble Alpes, Grenoble 38000, France
}

Corresponding Author Email: benazza13@yahoo.fr

https://doi.org/10.18280/mmc_a.931-404

Received: 26 February 2019

Accepted: 16 September 2020

\section{Keywords:}

EMC in the field of power electronics,

Electromagnetic disturbances, LISN, shielding,

common mode, differential mode, Buck chopper

\begin{abstract}
The aim of this study is to evaluate the influence of the position of a DC/DC static converter between a source and a load with regard to the conducted EMC emissions measured on the source. An experimental model was established through the analysis of relevant stresses, such as the variation in the lengths of the source-converter, converter-load cables and the impact of the shield connection. Through this study, it was observed that the circuit was sensitive to too large variations in the capacities of common mode and of the link, and the results obtained make it possible to confirm the reality of the electromagnetic pollution of the static DC/DC converter "Buck" as a function of connections. The results of this research can be used in DC/DC network designs based on buck converters.
\end{abstract}

\section{INTRODUCTION}

In recent years, the increase in equipment in automobiles and the need to reduce fuel consumption has led to the search for a less mechanical and more electric automobile.

To this end, the distribution of controls has become more and more electric and as a result a large number of static power converters are present.

Given this high proportion of converters based on the semiconductors used operate at higher and higher frequencies, this generates very restrictive electromagnetic disturbances.

These disruptions, which are part of the problems of electromagnetic compatibility (EMC) [1], are attracting more and more the attention of manufacturers, especially in the automotive field, which orients a more electric generation [2].

The generation of electromagnetic disturbances requires the implementation of an electrical model of electromagnetic compatibility based on power converters composed of semiconductors [3].

A set of environmental testing procedures to ensure that all equipment inside the automobile does not generate electromagnetic interference that compromises the operation of the equipment itself and those in its vicinity.

A circuit model for electromagnetic interference (EMI) of a DC-DC converter has been proposed.

The aim of this article is to use this generic circuit in order to place an experimental analysis approach of the disturbances emitted by DC/DC converters ("Buck" choppers) positioned, by two-wire cables between an LISN and the load. Therefore, it will be necessary to be able to identify the parameters of this circuit. This study is part of the electric power networks embedded complex in a car [49].
The overall configuration of our system is represented by the diagram of Figure 1.

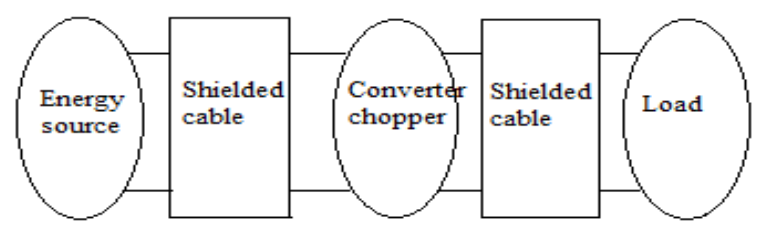

Figure 1. Overall representation of the experimental system

In order to achieve the main objective, experimental analyzes were carried out on the circuit following several configurations to validate the identification of the latter.

To solve this problem, this article establishes an experimental model based on a DC/DC converter "Buck" which it is connected to the input to the source via a shielded two-wire cable and to the output to a load via another shielded two-wire cable.

The electrical energy is transported in continuous form in the first two-wire link, which can be the seat of conducted disturbances due to the cutting of the chopper. These disturbances are measured by the LISN interposed between the source and the power cable. The load is connected to the converter via a shielded two-wire cable that contributes to the parasitic capacitances of the load with the earth, and therefore to the common mode current generation.

It will be recalled briefly that the disturbances conducted exist in two modes; common mode (CM) and differential mode (DM) [10-12]. These propagation paths are favored by the length of the cables, imposed by the arrangement of the different parts of the electrical system [13, 14]. According to several studies, common-mode disturbances are often 
considered to be the most restrictive [15-18]. Thus, on this theoretical basis, the explanatory diagram of the studied system is given in Figure 2.

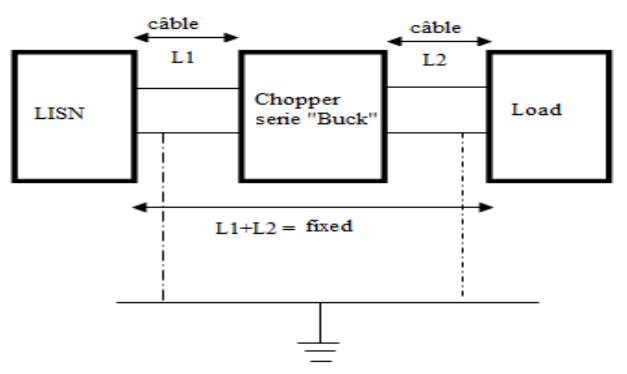

Figure 2. Full model in CM represented in block

According to several studies, conducted common-mode disturbances are often considered to be the most restrictive [19-21].

The results shed new light on the influence of cables in electrical circuits. The longer the lengths of the two-wire shielded cables are between the chopper and the source (LISN), the less disturbances there are and the shorter they are, the greater the disturbances and the greater the sensitivity of the circuit to excessive variations in the common mode capacities.

The rest of this document is organized as follows: Section 2 presents a preliminary study of which we present a simplified model, therefore we propose an equivalent diagram based on sources of disturbances to replace semiconductors in order to fully understand the path of the common mode current; Section 3 describes the presentation of the experiment of which we have presented three possible configurations for predicting EMC disturbances and we will end with a conclusion and perspectives.

\section{SIMPLIFIED MODEL}

In order to understand and justify our choice of the electric circuit based on a serial chopper, we will proceed to a preliminary study.

The overall model of this set can be reduced to the equivalent diagram shown in Figure 3. Note that the inductor $\mathrm{L}$ is inserted in the load and not in the chopper. The cable 2 is therefore subject to high voltage variations.

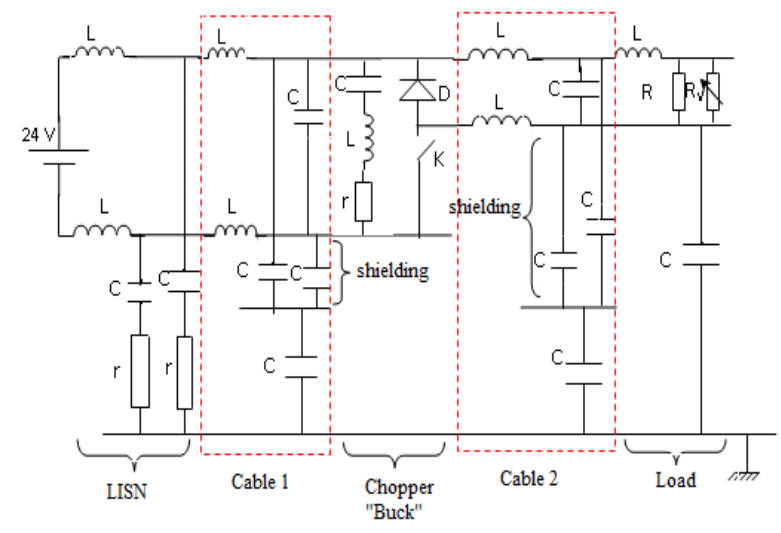

Figure 3. Circuit model connected to an LISN
In order to fully understand the common mode current path, an equivalent diagram based on disturbance sources is proposed to replace semiconductors (Figure 4).

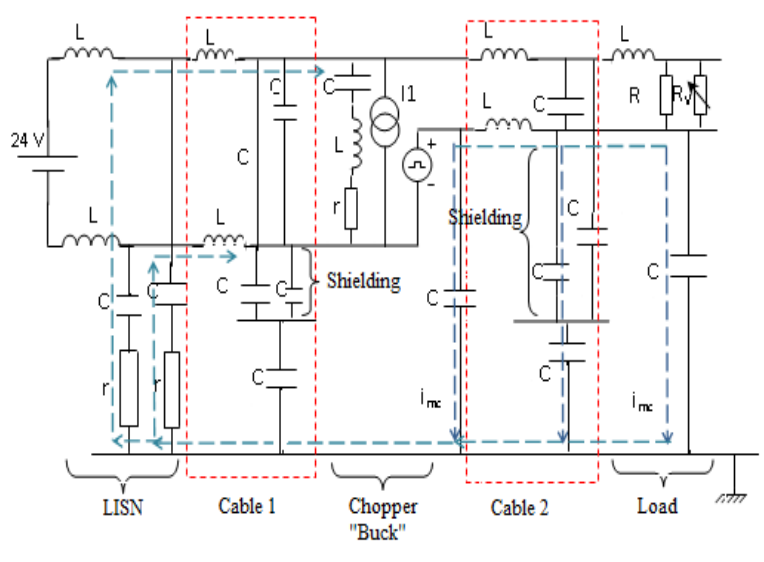

Figure 4. Model of the circuit connected to an LISN with a modeled chopper

Before looking at the possible measures, it is important to remember the context in which the converter works during its identification.

During the study, we have chosen to work with a simplified LISN [22-25], for reasons of simplicity of implementation to stay in the context of the EMC study, and to carry out measurements.

We start from a simplified study with an LISN, a cable1, a chopper series, a cable 2 and a load. The two cables are connected to the test bench mass, sometimes on the LISN side and sometimes on the load side.

Thus, we will see later the influence of the length of the upstream and downstream cables on the electromagnetic disturbances of the studied system. This simplified case is particularly interesting since the equivalent circuit can be easily identified.

\section{MEASURES AND INTERPRETATIONS}

\subsection{Presentation of the experimentation}

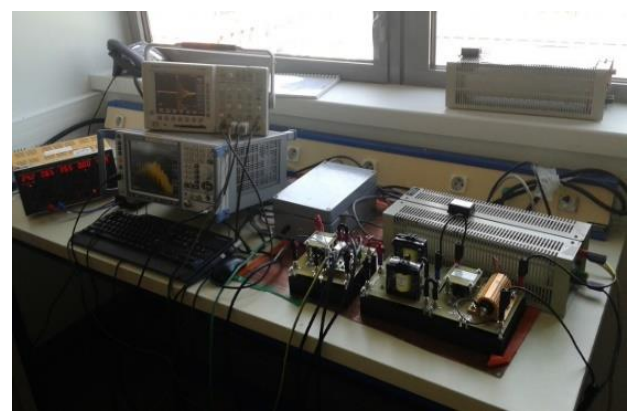

Figure 5. Test bench photograph: Power + LISN + Chopper "buck" + Load $(\mathrm{L}=2$ X $500 \mu \mathrm{H}, \mathrm{C}=8$ X $22 \mu \mathrm{F}, \mathrm{R}=100 \Omega)$ with an electronic oscilloscope and a spectrum analyzer

The DC-DC static converter in the study is a $100 \mathrm{~W}$ Buck chopper with an input voltage of $24 \mathrm{~V}$ for an output voltage of $12 \mathrm{~V}$.

Figure 5 shows a photograph of the test bench used which comprises a power supply, an impedance stabilization 
network (LISN), a "buck" chopper and a load ( $\mathrm{L}=2 \times 500$ $\mu \mathrm{H}, \mathrm{C}=8 \times 22 \mu \mathrm{F}, \mathrm{R}=100 \Omega$ ). An electronic oscilloscope and a spectrum analyzer were used for the measurements.

The Buck chopper is connected as input to an LISN via a two-wire shielded link (cable 1 of length L1-1) and output on a fixed load via another shielded two-wire link (cable 2 of length L2-2). (Table 1).

Table 1 shows the different lengths of the two-wire shielded cables used.

Table 1. Core length values

\begin{tabular}{ccc}
\hline Length & $\begin{array}{c}\text { LISN side } \\
\text { Cable 1 }\end{array}$ & $\begin{array}{c}\text { Load side } \\
\text { Cable 2 }\end{array}$ \\
\hline L1-1 & $5 \mathrm{~m}$ & $\mathrm{X}$ \\
L2-2 & $2.5 \mathrm{~m}$ & $5 \mathrm{~m}$ \\
& $\mathrm{X}$ & $2.5 \mathrm{~m}$ \\
\hline
\end{tabular}

Tests have also been done by either connecting the shielding of the cables or not to the plan of mass.

To visualize all temporal and frequency responses, an electronic oscilloscope and a spectrum analyzer were respectively used (Figure 6). Only the frequency responses will be presented in this study.

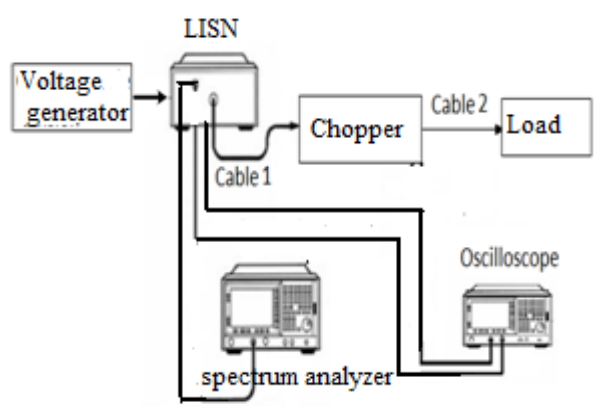

Figure 6. Block diagram of the manipulation

\subsection{EMC disturbance prediction}

To see the difference between the different results, we superimpose the two configurations as follows:

\subsubsection{Configuration 1}

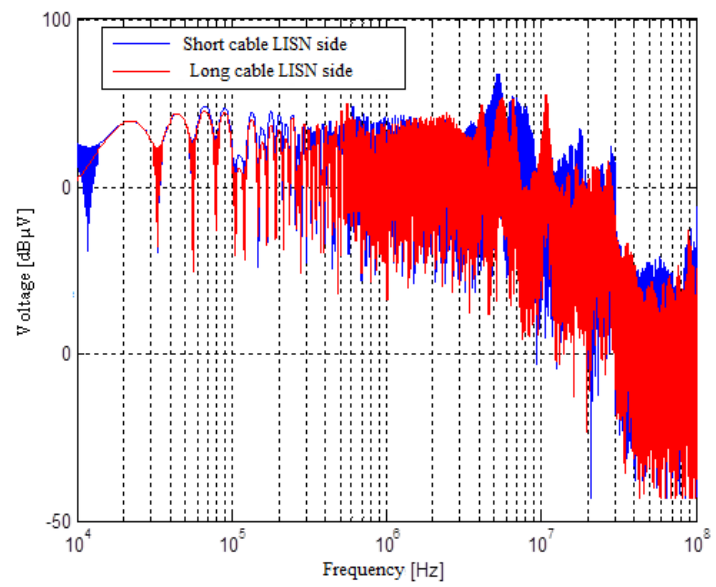

Figure 7. Frequency response of the LSIN voltage
$\mathrm{L} 1-1=5 \mathrm{~m}, \mathrm{~L} 2-2=2.5 \mathrm{~m}$

$\mathrm{L} 1-1=2.5 \mathrm{~m}, \mathrm{~L} 2-2=5 \mathrm{~m}$

The masses of the cables: 1 and 2 are not connected.

Figure 7 shows the frequency behavior of the LSIN voltage as a function of the influence of the chopper (buck) and the cables 1 and 2 (without connection to ground).

Several remarks must be made from this result:

The 1st spectrum (in red) for a long cable 1 between the source and the chopper is overall reduced, it is the impact of the CM capabilities of this source-side cable that reduce the disturbances measured on the LISN.

The 2nd spectrum (in blue); for a short cable 1 between the source and the chopper, the overall level is increased since the CM capacities of the load (including those of the cable 2 which is long) are larger, and those of the source are reduced. We also noticed the appearance of a resonance frequency peak at $5 \mathrm{MHz}$ and $10 \mathrm{MHz}$, which is due to the $\mathrm{CM}$ capacities and the inductance of the cable 2 .

\subsubsection{Configuration 2}

The same handling as the first case is maintained with the same cable lengths, but this time only the cable shield 1 is connected to the mass (Figure 8). The CM capabilities of this cable are therefore increased.

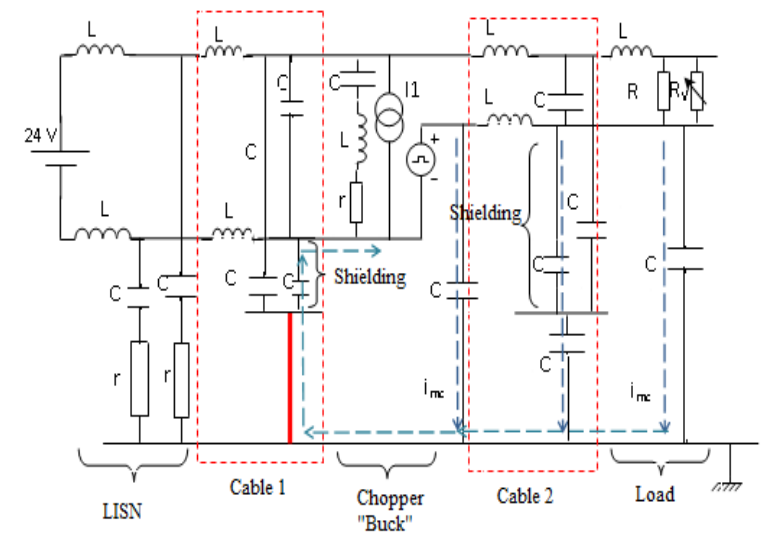

Figure 8. Model of the circuit connected to an LSIN with a chopper modeled and the cable 1 connected to the ground

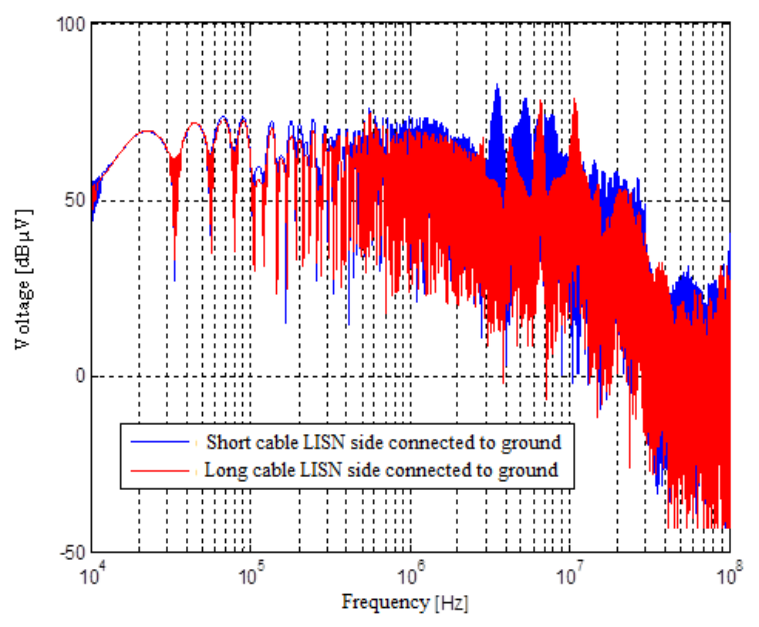

Figure 9. Frequency response of the LISN voltage whose shielding of the cable 1 is connected to the mass of the test bench 
Figure 9 shows the frequency response of the LSIN voltage as a function of the influence of the chopper (buck) and the shielded two-wire cables whose shielding of the cable 1 is connected to ground.

We see that for the 1 st spectrum (in red), for a long cable 1 between the source and the chopper, is reduced as compared to the 1st case which confirms the positive impact of $\mathrm{CM}$ capabilities.

For the second spectrum (in blue), it is noted that the increase in the length of the cable 2 generates an increase in common mode capabilities and therefore the spectrum. There is also a reduction in the frequency of resonance peaks due to this increase in CM capabilities.

\subsubsection{Configuration 3}

The same handling as the first case is maintained with the same lengths of the cables, but this time the shields of the two cables 1 and 2 are connected to the mass of the test stand (Figure 10).

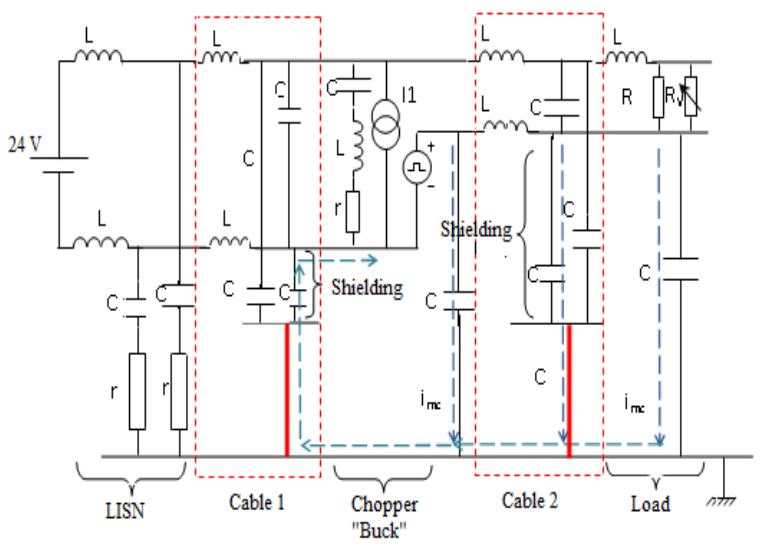

Figure 10. Model of the circuit connected to an LISN with a chopper modeled and the two cables 1 and 2 connected to ground

Figure 11 shows the frequency response of the LISN voltage whose shielding of the two cables 1 and 2 is connected to ground

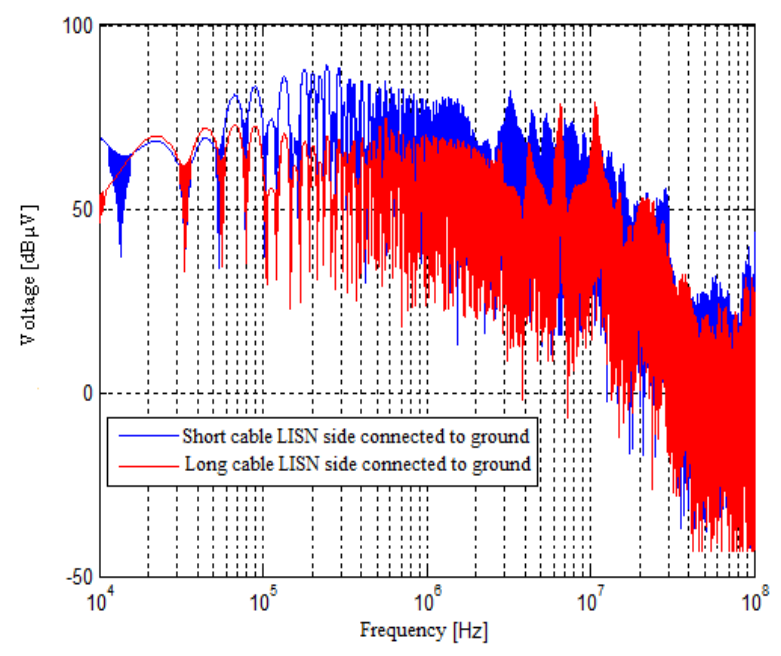

Figure 11. Frequency response of the LISN voltage whose shielding of the two cables 1 and 2 is connected to ground
The 1st spectrum (in red) for a long cable1 between the source and the chopper is reduced compared to the 1st and 2 nd cases. This is the most favorable case since the common mode capacities are maximum. In addition, the disturbances are directly replugged by the shields of the two cables connected to the mass and no longer pass through the LISN. Thus, the more cable 1 is long, the more resonance peak is reduced to $5 \mathrm{MHz}$.

The influence of the mass with respect to the electromagnetic disturbances is perfectly distinguished, from which the cable 1 acts as CM filtering, whereas the cable 2 emits disturbances in $\mathrm{CM}$.

\section{CONCLUSION}

The objective of this work was to understand how and why the connecting cables between the LISN source and the DCDC static converter have an influence on the EMC disturbances and how to minimize them. The longer the length of the two-core shielded cables between the chopper and the source (LISN), the less disturbances there are and the shorter they are the more disturbances are important.

The cable between the power supply and the converter has a role of filtering in $\mathrm{CM}$, while the cable between the chopper and the load emits disturbances in CM, the longer it is the more there are strong transmissions of common mode.

Thus we have seen in our example that the circuit was sensitive to too large variations in common mode capabilities and link. As a result, the cables were connected to the ground and the effect of the latter on the minimization of the IEM was seen.

The results obtained make it possible to confirm the reality of the electromagnetic pollution of the DC/DC "Buck" static converter as a function of the connections.

In terms of perspectives, it seems essential to carry out the study of a DC/DC network made up of converters which have been studied in simulation in a circuit under other forms of links (single-wire, twisted, etc.) with new conductive materials.

\section{ACKNOWLEDGMENT}

The authors are very grateful to Prof. Jean Luc. Schanen for his contribution to this experimental work and to facilate their task. This work was carried out in the polytechnic institute of Grenoble, electrical engineering laboratory G2E lab- University of Grenoble, France. It falls within the framework of training awarded to the first author for his doctoral thesis.

\section{REFERENCES}

[1] Payami, S., Behera, R.K., Iqbal, A., Al-Ammari, R. (2015). Common-mode voltage and vibration mitigation of a five-phase three-level NPC inverter-fed induction motor drive system. IEEE Journal of Emerging and Selected Topics in Power Electronics, 3(2): 349-361. https://doi.org/10.1109/JESTPE.2014.2313153

[2] Merabet, B., Vollaire, C., Sartori, C., Jettanasen, C. (2007). EMC of variable-speed drive systems in aeroplanes. 2EMC of IEEE Symposium on Embedded 
EMC, Rouen, France.

[3] Toure, B.B. (2012). Modélisation haute fréquence des variateurs de vitesse pour aéronefs: Contribution au dimensionnement et à l'optimisation de filtres CEM. Thèse de doct. Grenoble - France: Université Grenoble Alpes.

[4] Messaoudi, M., Videt, A., Idir, N., Boulharts, H., Vang, H. (2014). Modeling the residual common-mode voltage generated by 3-phase inverters with simultaneous-switching PWM strategies. 2014 IEEE Vehicle Power and Propulsion Conference (VPPC), Coimbra, pp.

$1-6$ http://dx.doi.org/10.1109/VPPC.2014.7007103

[5] Frantz, G. (2015). Approche système pour l'etude de la compatibilité électromagnétique des réseaux embarques. Thèse de Doctorat, Energie électrique. Université Grenoble Alpes. Français.

[6] Huynh, H.A., Joo, S., Kim, S. (2016). An experimental study of EMI reduction of DC-DC converter with frequency hopping technique. In Proceedings of the Electrical Design of Advanced Packaging and Systems, Honolulu, HI, USA, pp. 107-109.

[7] Lu, N.J., Hredzak, B. (2018). Current ripple reduction for photovoltaic powered single-phase buck-boost differential inverter under nonlinear loads. 2018 7th International Conference on Renewable Energy Research and Applications (ICRERA), Paris, France, pp. 544-548.

http://dx.doi.org/10.1109/ICRERA.2018.8566746

[8] Chikhi, N., Bendaoud, A., Slimani, H., Benazza, B., Miloudi, H. (2015). Génération des perturbations dans un hacheur et identification des chemins de propagation vers le réseau électrique. 9ème Conférence sur le Génie Electrique EMP, Bordj El Bahri, Alger.

[9] Benazza, B., Bendaoud, A., Reineix, A., Dafif, O., Slimani, H. (2019). Experimental study of the behaviour of the crosstalk of shielded or untwisted-pair cables in high frequency. Serbian Journal of Electrical Engineering, 16(3): 311-324 https://doi.org/10.2298/SJEE1903311B

[10] Brovont, A., Cuzner, R. (2018). Modeling commonmode circulating currents in paralleled non-isolated DCDC converter-based systems. 2018 IEEE Energy Conversion Congress and Exposition (ECCE), Portland, pp. 4187-4194. http://dx.doi.org/10.1109/ECCE.2018.8558277

[11] Brovont, A.D., Cuzner, R.M. (2018). DM and CM modeling of non-isolated buck converters for EMI filter design. 2018 IEEE Transportation Electrification Conference and Expo (ITEC), Long Beach, CA, USA, pp. $140-145$ http://dx.doi.org/10.1109/ITEC.2018.8450232

[12] Benhadda, N., Bendaoud, A., Chikhi, N. (2018). A conducted EMI noise prediction in DC/DC converter using a frequency-domain approach. Elektrotehniški Vestnik Journal, 85(3): 103-108.

[13] Durier, A., Marot, C., Crepel, O. (2013). Using the EM simulation tools to predict the Conducted Emissions level of a DC/DC boost converter: Introducing EBEMCE model. 2013 9th International Workshop on Electromagnetic Compatibility of Integrated Circuits (EMC Compo), Nara, pp. 152-157. https://doi.org/10.1109/EMCCompo.2013.6735191
[14] Miloudi, H., Bendaoud, A., Miloudi, M. (2017). A method for modeling a common-mode impedance for the AC motor. Elektrotehniški Vestnik Journal, 84(5): 241-246.

[15] Costa, F., Vollaire, C., Meuret, R. (2005). Modeling of conducted common mode perturbations in variablespeed drive systems. IEEE Transactions on Electromagnetic Compatibility, 47(4): 1012-1021. http://dx.doi.org/10.1109/TEMC.2005.857365

[16] Zhu, N., Xu, D, Wu, B., Zargari, N.R., Kazerani, M., Liu, F. (2013). Common-mode voltage reduction methods for current-source converters in mediumvoltage drives. IEEE Transactions on Power Electronics, 28(2): https://doi.org/10.1109/TPEL.2012.2201174

[17] Slimani, H., Bendaoud, A., Reguig, A., Benazza, B., Reineix, A., Dafif, O. (2016). Experimental study of coupling between an electromagnetic wave and transmission lines in a GTEM cell. Journal of Electrical Engineering, 16(1): 195-203.

[18] Meynard, T., Cougo, B., Brandelero, J. (2013). Design of differential mode filters for two-level and multicell converters. IEEE 11th International Workshop of Electronics, Control, Measurement, Signals and their application to Mechatronics (ECMSM), Toulouse, pp. 1-6. http://dx.doi.org/10.1109/ECMSM.2013.6648963

[19] Zhai, L., Zhang, T., Cao, Y., Yang,S.P., Kavuma, S., Feng, H.Y. (2018). Conducted EMI prediction and mitigation strategy based on transfer function for a high-low voltage DC-DC converter in electric vehicle. Energies, $11(5)$ : 1028. https://doi.org/10.3390/en11051028

[20] Pignari, S.A., Orlandi, A. (2003). Long cable effects on conducted emissions levels. IEEE Transactions on Electromagnetic Compatibility, 45(1): 43-54. https://doi.org/10.1109/TEMC.2002.808023.

[21] Zhai, L., Zhang, X.Y., Bondarenko, N., Loken, D., Van Doren, T.P., Beetner, D.G. (2016). Mitigation emission strategy based on resonances from a power inverter system in electric vehicles. Energies, 9(6): 419. http://dx.doi.org/10.3390/en9060419

[22] Taki, J., Robert, F., Bensetti, M., Dessante, P., Sadarnac, D. (2016). Modélisations orientées CEM d'un convertisseur de puissance pour une optimisation multiphysique. Symposium de Génie Electrique, Grenoble, France.

[23] Bodo, N., Jones, M., Levi, E. (2014). A space vector PWM with common-mode voltage elimination for open-end winding five-phase drives with a single DC supply. IEEE Transactions on Industrial Electronics, 61(5): 2197-2207. http://dx.doi.org/10.1109/TIE.2013.2272273

[24] Miloudi, H., Bendaoud, A., Miloudi, M., Tounsi, F. (2014). Long cable effect on the electromagnetic perturbation génerated by three phase inverter-fedmotor drives. The 3rd international conference on information processing and electrical engineering, ICIPEE, Tebessa, 14: 24-25.

[25] Chu, Y.B., Wang, S. (2015). A generalized commonmode current cancelation approach for power converters. IEEE Transactions on Industrial Electronics, 62(7): 4130-4140. https://doi.org/10.1109/TIE.2014.2387335 